\title{
Música e banda: tessitura da inserção social no Piauí \\ (1905-1948)
}

\author{
Músic and brass band: the fabric of its social insertion \\ in Piaui (1905-1948) \\ PEDRO THIAGO COSTA MELO@a ; \\ EDNARDO MONTEIRO GONZAGA DO MONTIDb
}

\section{Resumo}

Este artigo tem as bandas de música como foco de análise histórica a partir da tessitura de sua inserção social no Piauí, entre anos 1905 e 1948. Bibliograficamente, alinha-se com Queiroz (1998), Filho (2009), Monti (2015) e Elias (1993). As fontes hemerográficas e os demais dados foram tratados e organizados a partir dos pressupostos teóricometodológicos da Nova História (BURKE, 1991). Nessa perspectiva, foi possível perceber que o fenômeno musical no Piauí está conectado à concepção de civilizar, relacionando-se com a educação. Também se percebe que as bandas de música estavam em vários espaços de sociabilidade: encontros políticos, inaugurações, eventos da municipalidade, sociedades artísticas, mecânicas e liberais, clubes sociais, festas patrióticas e religiosas e instituições educativas, sendo consideradas um dos elementos significativos de avanços do processo civilizatório de outrora.

Palavras-chave: História da Educação Musical. Bandas de música. Piauí.

\section{Abstract}

This article has brass bands as focus of historical analysis from the fabric of its social insertion in the State of Piauí, between 1905 and 1948. Bibliographically, it is aligned with Queiroz (1998), Filho (2009), Monti (2015), and Elias (1993). The hemerographic sources and other data were compiled and organized from the theoretical-

\footnotetext{
a Universidade Federal de Santa Maria (UFSM), Santa Maria, RS, Brasil. Doutorando em EDUCAÇÃO e Mestre em EDUCAÇÃO, e-mail: pedrothiagocostamelo@gmail.com;

b-Universidade Federal do PIAUÍ (UFPI), Teresina, PI, Brasil. Doutor em Educação, e-mail: ednardo@ufpi.edu.br
} 
methodological framework of New History (BURKE, 1991). In this perspective, it was possible to perceive that the musical phenomenon in Piauí is connected to the civilizing conception, in relation to education. In addition, it is perceptible that the brass bands were present in various spaces of sociability: political meetings, inaugurations, municipal events, artistical, mechanical and liberal societies, social clubs, patriotic and religious parties and educational institutions, being considered one of the significant elements of advances in the erstwhile civilizing process.

Keywords: Lorem. History of Musical Education. Brass bands. Piauí.

\section{Resumen}

Este artículo plantea los grupos musicales como foco del análisis histórico desde la tesitura de su inserción social en Piauí, entre los años 1905 y 1948. Bibliográficamente, se alinea a Queiroz (1998), Filho (2009), Monti (2015) y Elias (1993). Las fuentes hemerográficas y los otros datos se analizaron y se organizaron desde los presupuestos teóricos y metodológicos de la Nueva Historia (BURKE, 1991). A partir de esa perspectiva, se pudo percibir que el fenómeno musical en Piauí se conecta a la concepción de civilizar, relacionándose a la educación. Del mismo modo, se notó que los grupos musicales estaban en muchos espacios de sociabilidad: encuentros políticos, inauguraciones, eventos de la municipalidad, sociedades artísticas, mecánicas y liberales, clubes sociales, fiestas patrióticas y religiosas e instituciones educacionales, como elemento significativo de avance en el proceso civilizatorio de otrora.

Palabras-clave: Historia de la Educación Musical. Grupos musicales. Piauí.

\section{Introdução}

Lorem ipsum Geraldo Viramundo, em suas andanças, na loucura de acreditar num mundo justo, ficou admirado com um sujeito tocando uma tuba. Esse sentimento veio de sua infância; ele era fascinado por instrumentos musicais. Depois da admiração e contemplação do belo, adentra a cidade na qual muitos moradores tocavam instrumentos e formavam uma banda com os recursos possíveis - porém, com bastante amor. Essa passagem da obra de Fernando Sabino, "O grande Mentecapto", poderia se referir a um grupo musical como muitos outros e é sintomática de um fato social: a música está relacionada à história dos povos, e uma parte disso está relacionada às bandas de música (SCHWARCZ; STARLING, 2018). Elas foram e ainda são um dos principais modos de formação de músicos no Brasil. Exerceram diversas funções ao longo do tempo e na sociedade em que estiveram situadas. É “[...] difícil alguém que não tenha se deparado com 


\section{Música e banda: tessitura da inserção social no Piaú (1905-1948)}

uma banda de música em um coreto da cidade, somos acostumados a vê-las atuando em salas de concerto, desfiles cívicos e animando eventos políticos" (SILVA, 2010, p. 1).

No Piauí, não foi diferente. No limiar do século XX, as bandas estavam presentes nos mais variados espaços. Segundo Queiroz (1998), a música, no início do século XX, estava no centro da vida social piauiense, boa parte dela "[...] através da participação em alguma banda ou fanfarra" (FILHO, 2009, p. 17). Tendo isso em vista, surge o seguinte problema de pesquisa: como estavam inseridas as bandas de música no Piauí?

Para viabilizar a solução do citado problema de pesquisa, metodologicamente, fizemos um recorte temporal, de 1905-1948. A razão dessa escolha se desdobra nos aspectos elencados a seguir: 1 - no início do século XX, a música estava no centro da vida social piauiense; 2 - há possibilidade de agregar análise pelas ocorrências (frequência), através da mineração de texto ${ }^{1}$; e 3 - há outras fontes que abarcam esse recorte e tema.

A fim de responder a essas questões, analisamos, numa perspectiva histórica, as bandas do Piauí a partir da mobilização bibliográfica, que abarca estudos de Queiroz (1998), Filho (2009), Monti (2015) e Elias (1993). Correlacionamos tais trabalhos com fontes hemerográficas, mais especificamente Diário do Piauí, O Apóstolo, Gazeta, O Monitor e O Artista, coletadas no site da Hemeroteca Nacional e no Arquivo Público do Estado do Piauí. E por que escolhemos os jornais como fonte? Porque são um registro de alto valor social. Para Nóvoa (1993), é possivelmente o melhor meio para compreensão da articulação entre teoria e prática de um discurso educacional. Portanto, os jornais são reveladores das “[...] condições estruturais, sistemas de valores, normas e símbolos e tem a magia de transmitir, através de porta vOz, as representações de grupos determinados, em condições históricas, sócio econômicas e culturais específicas" (MINAYO 2000, p. 103).

Nesse sentido, os jornais, no domínio da história da educação, têm grande relevância, pois sua observação permite captar os rastros e vestígios pelas formas de fazer no cotidiano (CERTEAU, 1994). Ademais, “[...] um meio indispensável para o conhecimento [...], o que ele representa, por exemplo, no espaço onde se desenvolve e onde se localizam todos os

\footnotetext{
${ }^{1}$ A Mineração de Texto (MT) é o processo de interação com uma coleção de documentos textuais utilizando um conjunto de ferramentas de análise da informática, que visa à descoberta de informações novas, ou desconhecidas, por meio da extração automática dos dados em documentos escritos (AZEVEDO; BASTOS, 2015).

Rev. Caminhos da Educação: diálogos, culturas e diversidades, Teresina, v. 3, n. 1, p. 19-34, Jan./Abr. 2021
} 
sistemas, teorias e práticas educacionais" (CASPARD; CASPARD, 1997, p. 32-33). Isso se torna possível frente ao novo quadro teórico-metodológico de expansão pela qual passou e ainda passa a História como uma ciência humana, a partir da abertura iniciada com os Annales, na Nova História, que permitiu ao historiador infinitas possibilidades de objetos, fontes e situações-problema de estudo (BURKE, 1991).

Este escrito encontra-se dividido em duas seções, além das considerações finais. A primeira realiza uma reflexão sobre o fenômeno da música no Piauí; e a segunda analisa as bandas de música entre os espaços de sociabilidade. Com isso, foi possível vislumbrar uma tessitura da inserção social das bandas no Piauí.

\section{Fenômeno da música no Piauí}

No século XX, as pautas "civilizatórias", “modernas", estavam fortemente impregnadas na vida social piauiense (QUEIROZ, 1998). Na formação considerada ideal, operavam as dimensões do avanço do processo civilizador, como a boa música, sinal de refinamento social e distinção. Esse processo, produto do autocontrole, e o itinerário dessa proposta são o que Elias (1993) entende como a transformação que envolve coerção externa (penalidades, punições, prisões) e autocoerção (educação, civilidade, cortesia), no qual a educação e a civilidade têm maior destaque. Entende-se que, assim,

\footnotetext{
Mostramos como o controle efetuado através de terceiras pessoas é convertido, de vários aspectos, em autocontrole, que as atividades humanas mais animalescas são progressivamente excluídas do palco da vida comum e investidas de sentimentos de vergonha, que a regulação de toda a vida instintiva e afetiva por um firme autocontrole se torna cada vez mais estável, uniforme e generalizada. Isso tudo certamente não resulta de uma ideia central concebida há séculos por pessoas isoladas, e depois implantada em sucessivas gerações como a finalidade da ação e do estado desejados, até se concretizar por inteiro nos "séculos de progresso". Ainda assim, embora não fosse planejada e intencional, essa transformação não constitui uma mera sequência de mudanças caóticas e não estruturadas (ELIAS, 1993, p. 193-194).
}

Então, entende-se que o processo civilizador é transformador social, de forma a serem compreendidos o refinamento e a distinção como sua consequência. A música também se insere nesse projeto. Segundo Monti (2015), as atividades de educação musical nas décadas iniciais do século XX — com a influência da Escola Nova —; as experiências educacionais musicais; e as práticas pedagógicas inovadoras ou em teste no Brasil eram significativas no contexto educacional brasileiro na Era Vargas. Com o objetivo de formar 
Música e banda: tessitura da inserção social no Piauí (1905-1948)

cidadãos, pessoas "mais civilizadas", adaptadas às modernidades dos países desenvolvidos, a música era até vinculada a propostas higienistas.

[...] significava uma autêntica aproximação e consonância com a educação pretendida pelos intelectuais da Escola Nova. O grupo tinha como objetivo formar cidadãos, homens 'mais civilizados' [...] ligou-se à proposta escolanovista de Afrânio Peixoto, dentre outros aspectos, pela perspectiva higienista defendida pelo médico, que com os seus esforços trabalhava objetivando uma nação mais saudável. Nesse sentido, a prática do canto coletivo nas escolas brasileiras era mais uma possibilidade de promover a ginástica para os pulmões. Simultaneamente, a atividade [musical] era capaz de proporcionar leveza pela experiência estética, num contexto de denso trabalho físico e mental, que demandava, além da formação docente, a experimentação com as crianças (MONTI, 2015, p. 240241).

Acreditava-se que a música produzia na alma uma cultura interior que faz parte da educação do povo. Nesse sentido, tinha por efeito desenvolver os vários órgãos do ouvido e da palavra, “[...] adoçar os costumes, civilizar as classes inferiores, aligeirar para elas as fadigas do trabalho, e proporcionar-lhes um inocente prazer, em vez de distrações muitas vezes grosseiras e arruinadoras" (BARBOSA, 1947, p. 103). A música no Piauí tinha esse condão, pois estava, como ressalta Queiroz (1998), em posição de destaque na capital, Teresina, caixa de ressonância de todo o estado. A música, no

[...] século XX, está no centro da vida social. É imprescindível em solenidades cívicas, passeatas e eventos familiares, como casamentos, batizados, aniversários, formaturas, nos bailes - que são a principal diversão da cidade [...]. Além dos usos regulares e tradicionais da Música, no início deste século aparecem novas formas de lazer que requerem sua utilização ou em que ela é o próprio centro, como as tocatas familiares, os números executados durante e nos intervalos das sessões cinematográficas e as famosas retretas no Jardim Praça Rio Branco (QUEIROZ, 1998, p. 52-53).

Convém ressaltar que, nesse período, a cidade de Teresina passou por transformações que acarretaram desdobramentos nos costumes, como acima citado. É a construção do ideário moderno. Esse fenômeno não é uma especificidade da cidade de Teresina. Segundo Schwarcz e Starling (2015), o intuito "civilizatório" foi primeiramente manifestado no Rio de Janeiro, em 1902, pelo presidente Rodrigues Alves. O mesmo ocorreu em São Paulo e Belo Horizonte, pois era preciso embelezar as principais cidades. Entendia-se que tais alterações levariam a mudanças no comportamento da população local, a novos hábitos sociais. "Além dos usos regulares e tradicionais da Música, no início deste século aparecem 
novas formas de lazer que requerem sua utilização ou em que ela é o próprio centro, como as tocatas familiares" (SCHWARCZ; STARLING, 2015, p. 276). No Piauí, foi urgente entrar nessa nova rota social.

Essas providências mais se fazem necessárias no Piauí, estado principiante, paupérrimo, cuja indústria única é a pastoril. Desgraçadamente, porém, apesar de contar mais de dois séculos de existência, ela não tem saído de um período por demais rudimentar. O gado nasce e cresce pelos campos, sem cuidados higiênicos, sem a assistência de um veterinário, entregue em definitivo a boa vontade do vaqueiro que comumente sabe derribar uma vez, capar um garrote, curar bicheiras com a aplicação do mercúrio, e nada mais (JORNAL NORTISTA, 1901, p. 2).

A conjuntura da economia piauiense era favorável, nos primeiros anos do século XX, a essas pretensões. Teria sido determinada pela borracha da maniçoba, que, a despeito de não ter provocado alterações fundamentais no sistema de propriedade da terra ou nas relações de trabalho, certamente teria contribuído para a efetiva autonomia do Estado na fase de consolidação do sistema republicano. A estabilidade econômica, e ao mesmo tempo a estabilização do novo regime, com a delineação de funções administrativas nas alçadas federal, estadual e municipal, permitiu a solidez e um continuísmo para o futuro.

Nesse clima, temos o surgimento dos primeiros clubes de música no Piauí, no início do século XX, ensejando a movimentação cultural causada por eles nos anos seguintes. Queiroz (1998) assevera que os clubes de música surgem em Teresina em 1907 — Clube Lítero-Musical e o Clube Monteverdi —, com sócios de ambos os sexos e, em geral, orientados por professores de Música. "Esses clubes tiveram atuação pelo menos até 1909" (QUEIROZ, 1998, p. 53).

O desenvolvimento da música, em posição de destaque, pode também ser sustentado a partir da constatação de sua forte presença nos jornais piauienses. A mineração de texto realizada na Hemeroteca Nacional detectou 797 ocorrências da palavra música em 83 acervos digitalizados. Apenas no periódico Diario do Piauhy: Orgão Official dos Poderes do Estado, entre 1911 a 1914, temos 37 ocorrências iguais a esta: 
Figura 1 - Anúncio da Vitrola Victor

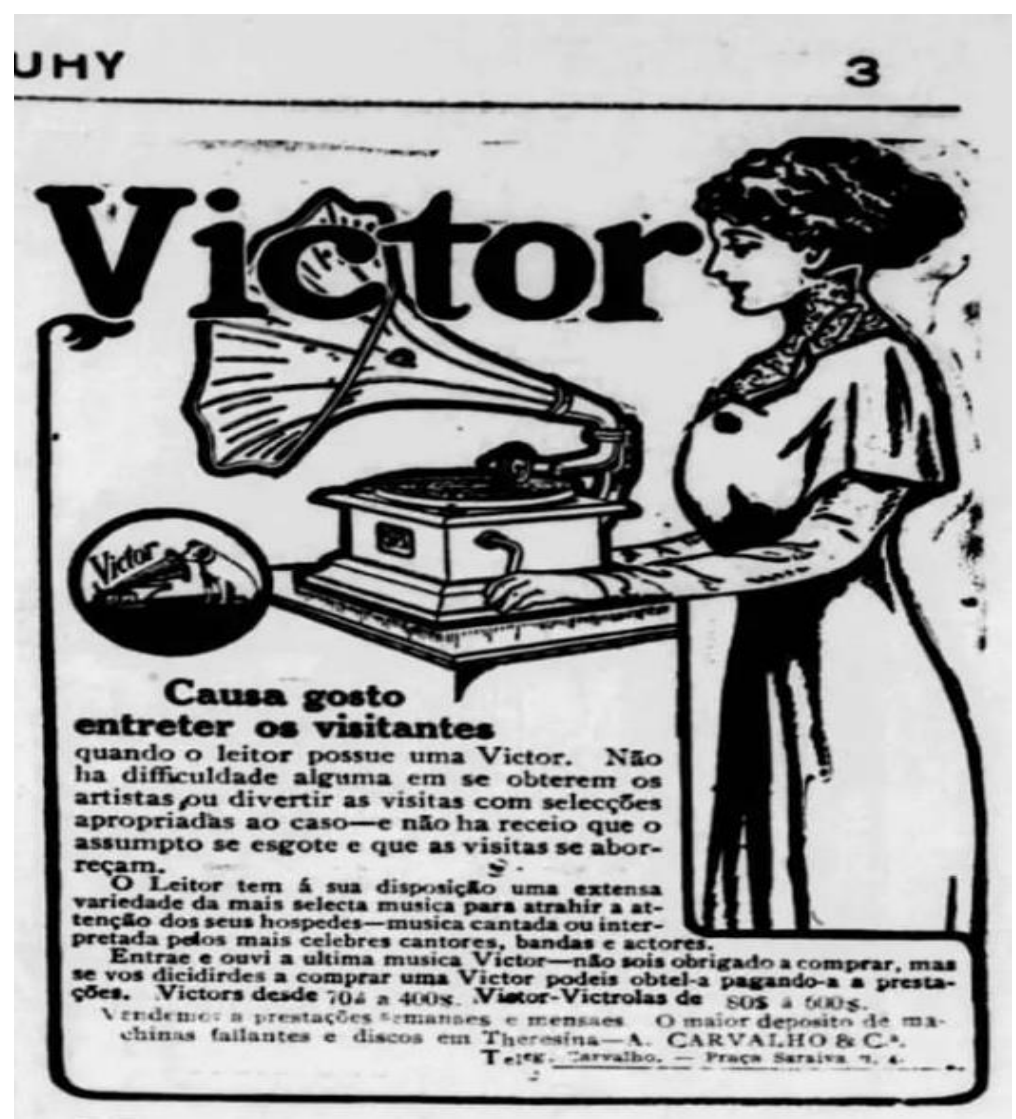

Fonte: Causa... (1912, p. 3).

A Victor era um instrumento (vitrola), e seu objetivo era, como ficou posto no anúncio, "Causa[r] gosto [e] entreter os visitantes" quando o possuíam. "Não há dificuldade alguma em se obterem os artistas ou divertir as visitas com seleções apropriadas ao caso e não há receio que o assumto se esgote e que as visitas se aborreçam" (CAUSA..., 1912, p. 3). O anúncio foca na transmissão de um gosto pelo lazer dentro do cotidiano, como um convite, um bem de contato cultural importante, apropriado. Pela análise nos jornais, correlacionada com a bibliografia aqui abordada, o que podemos perceber é a música como um fenômeno social no Piauí.

Nesse panorama social, as bandas, outro veículo de acesso à música dentro desse contexto, tem forte presença. A amostra hemerográfica da primeira metade do século XX, 
especificamente entre 1905 a 1948, revela a presença das bandas de música no Piauí entre os diversos espaços sociais, como abordamos a seguir.

\section{Bandas de música: nos espaços de sociabilidades}

São abundantes nos jornais, especificamente de 1905 a 1948, notícias da presença das bandas nos mais variados espaços sociais do Piauí. Esses documentos foram encontrados em grande parte dos jornais que se encontram digitalizados no acervo Hemeroteca Nacional: há 789 ocorrências, nos 83 acervos do Piauí, atinentes a bandas musicais no período supracitado.

Boa parte das notícias dos jornais estão relacionadas a visitas festejadas. Um exemplo disso é a chegada a Teresina do senador Joaquim Ribeiro Gonçalves. A acolhida foi acompanhada ao som da harmoniosa peça executada pela banda do corpo militar de polícia (DE AMARANTE, 1911), a banda mais antiga em funcionamento. Foi criada pela Resolução $n^{\circ}$ 909, de 17 de julho 1875, pelo Presidente da Província Delfino Cavalcante de Albuquerque. Inicialmente, foi “composta de 20 músicos que foram adidos ao Corpo, vindos do Internato Artístico" (ROCHA SOUSA, 2014, p. 36).

As festas de caráter político tinham nas bandas um dispositivo para agregar pessoas e entusiasmar a população. A banda do corpo militar de polícia e a banda Lyra CampoMaiorense são um exemplo de polo aglutinador, um elo de contato com os participantes da política e seus eleitores. Isso é noticiado em 1912, na conferência política sobre a candidatura de Miguel Rosa realizada por Domingos Monteiro, em Campo Maior. As supracitadas bandas executaram, durante a festa, bonitas peças de seu repertório, deixando o povo entusiasmado (CAUSA..., 1912).

A presença das bandas também se dava nas festas civis, como no 7 de Setembro. Conforme sinalizam os documentos, em Amarante, em 1911, a banda de música Euterpe Amarantina gentilmente se prestou para o ato cívico; executou as mais belas peças de seu repertório, recebendo condignamente os que se aproximavam da reunião. Sendo assim, os jornais noticiavam que "a cidade comemorou dignamente, debaixo do mais vivo enthusiasmo de uma parte de seus habitantes, a grande data nacional- 7 de setembro" (DE AMARANTE, 1911).

A Euterpe Amarantina também se apresentava em outras cidades do Piauí. Um exemplo disso foi sua presença em um evento considerado jubiloso, digno de nota, na cidade de Regeneração. Ocorreu a inauguração da usina a vapor, de propriedade do coronel João Rev. Caminhos da Educação: diálogos, culturas e diversidades, Teresina, v. 3, n. 1, p. 19-34, Jan./Abr. 2021 
Música e banda: tessitura da inserção social no Piauí (1905-1948)

Ribeiro Gonçalves Filho (INAUGURAÇÃO..., 1909). Segundo a imprensa, para coroar o evento, que se dava como um pontapé para o progresso da região, a orquestra da Euterpe Amarantina deleitava, com seus sons harmoniosos, o seleto auditório que compareceu à solenidade (INAUGURAÇÃO..., 1909).

As notícias do período indicam que as bandas de música também eram criadas pelos gestores municipais, que acreditavam, com isso, dotar a cidade de música e civilidade, como podemos observar a seguir:

Figura 2 - "Jazz-Band de Campo Maior"

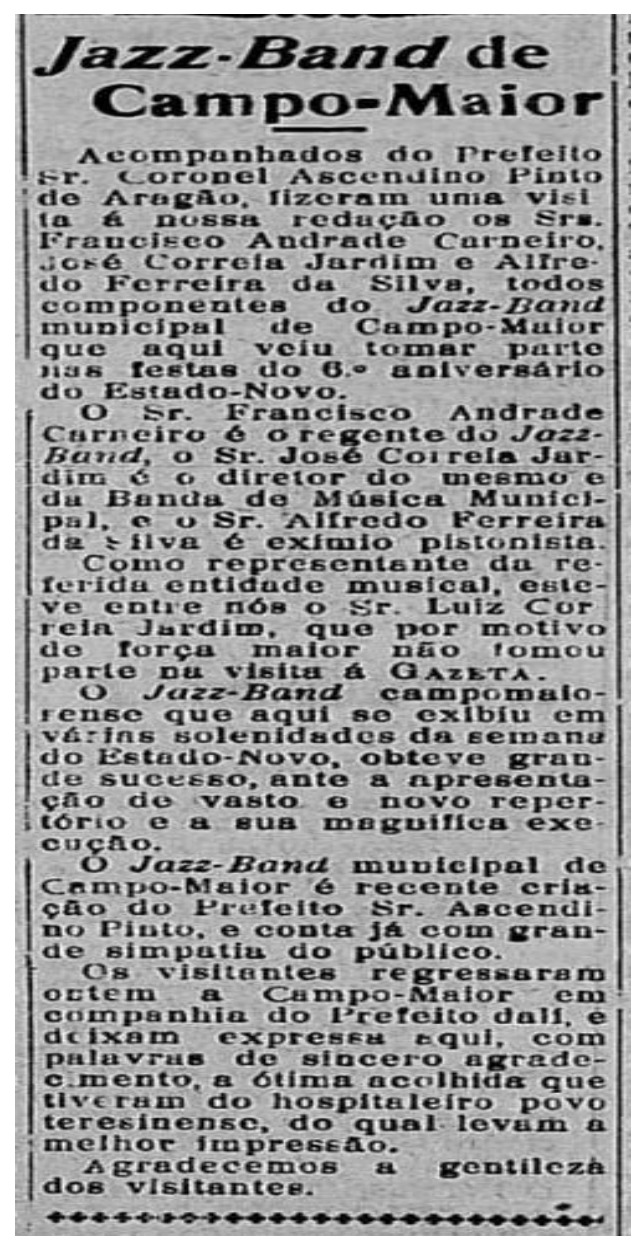

Fonte: Jazz-Band... (1943, p. 4).

Uma banda municipal para deixar a melhor impressão aos visitantes: é assim que se justificou o surgimento da banda Jazz-Band campo-maiorense. Para além disso, havia as Rev. Caminhos da Educação: diálogos, culturas e diversidades, Teresina, v. 3, n. 1, p. 19-34, Jan./Abr. 2021 
sociedades artísticas, mecânicas e liberais que criavam suas bandas, como a "Artistico FootBall Club", de Teresina, criada em 1918; e a "Sociedade União Progressista dos Artistas Mechanicos e Liberais de Parnahyba", fundada em 1919. A primeira tinha de capital as “joias" de seus sócios; destinava, segundo seu estatuto, parte disso para contratar uma banda de música para seus metches e festas (ESTATUTOS..., 1918, p. 3). A segunda tinha como uma de suas bases de fundação, em seu artigo 6, "Manter uma banda de Muzica exclusivamente de artista e operarios" (ESTATUTOS..., 1918, p. 3).

As bandas de música também estavam presentes nas festividades religiosas, como podemos constatar nas notícias dos jornais. Segundo consta nas fontes, em 1907, ocorreu a Festa do Sagrado Coração de Jesus em Teresina. O jornal O Apostolo a descreve como um “expledor. [...] encerrava o prestito o Revdmo. Parocho, a banda de música e grande massa popular" (UNIÃO..., 1907, p. 4). Melo (2019) corrobora essa assertiva ao citar a obra O Manicaca, do piauiense Abdias Neves, como um documento que traz indícios do cotidiano da Teresina do século XX. A cidade era eivada de religiosidade católica e de sua versão popular carregada de misticismos, contexto no qual as festividades religiosas eram acompanhadas dos sons de bandas.

Na cidade de Parnaíba, também ocorriam eventos do mesmo viés. Segundo os impressos da época, 1912, foi oferecido pela redação do jornal O Rebale um suntuoso banquete ao padre Olegario Memoria. Sugere-se que houve grande comparecimento, tocando a banda de música Pedro Braga (CAUSA..., 1912). Da mesma maneira, há menção ao aniversário do Bispo, que não deixou de ter a presença de uma banda de música. Como podemos ver a seguir, a presença da banda "Harmonia Parnahybana", dirigida pelo capitão Pedro Braga, significa "a mais justa prova de amor" ao Bispo Dom Joaquim, com repertório do gosto do aniversariante. 
Figura 3 - "Anniversario do Sr. Bispo"

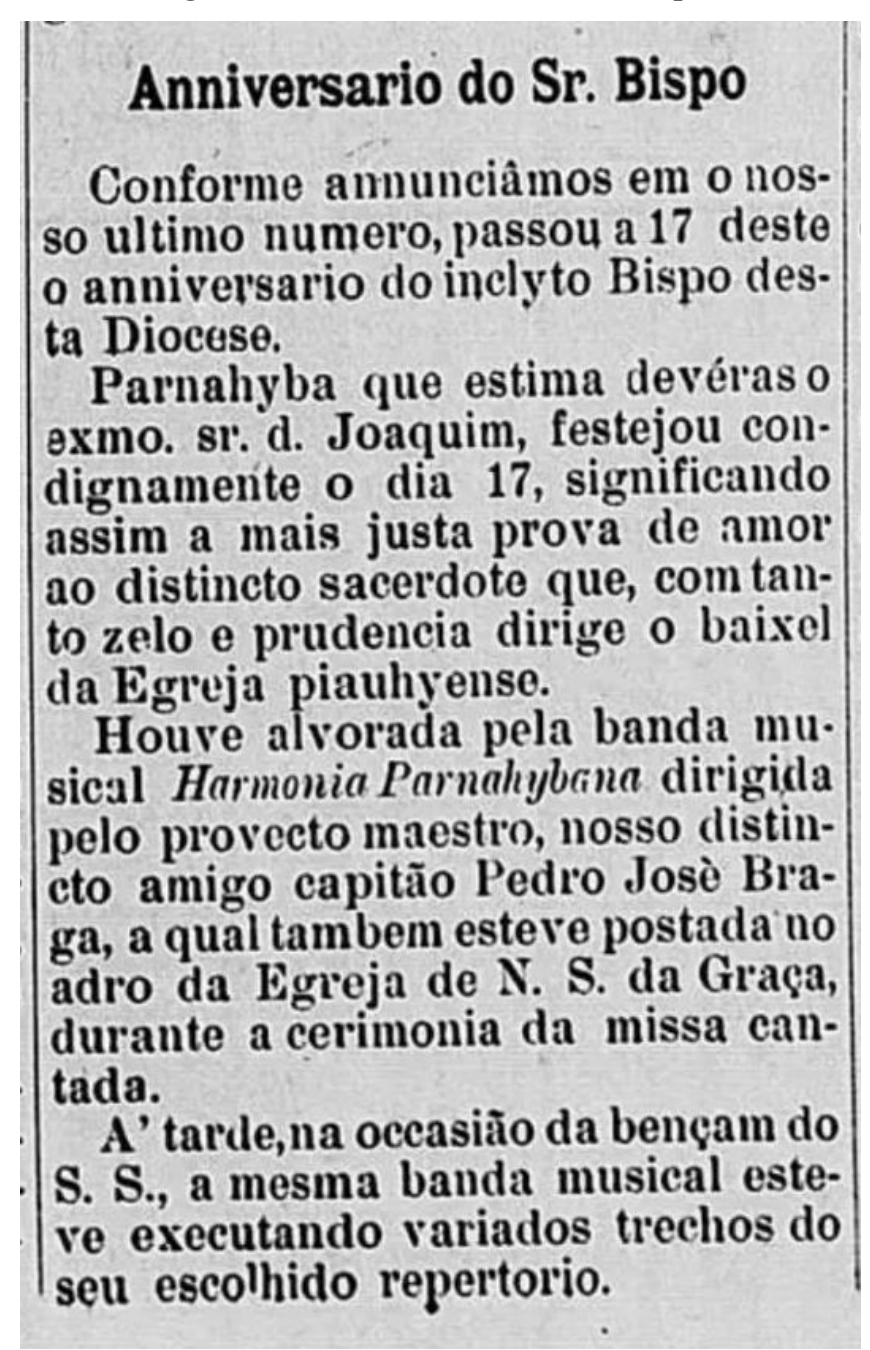

Fonte: União... (1907, p. 3).

Os grupos musicais também eram criados pelas instituições educativas, sejam em Ginásio ou Seminário, como podemos acompanhar nos jornais da época: 
Figura 4 - "O Dia do Soldado em Floriano"

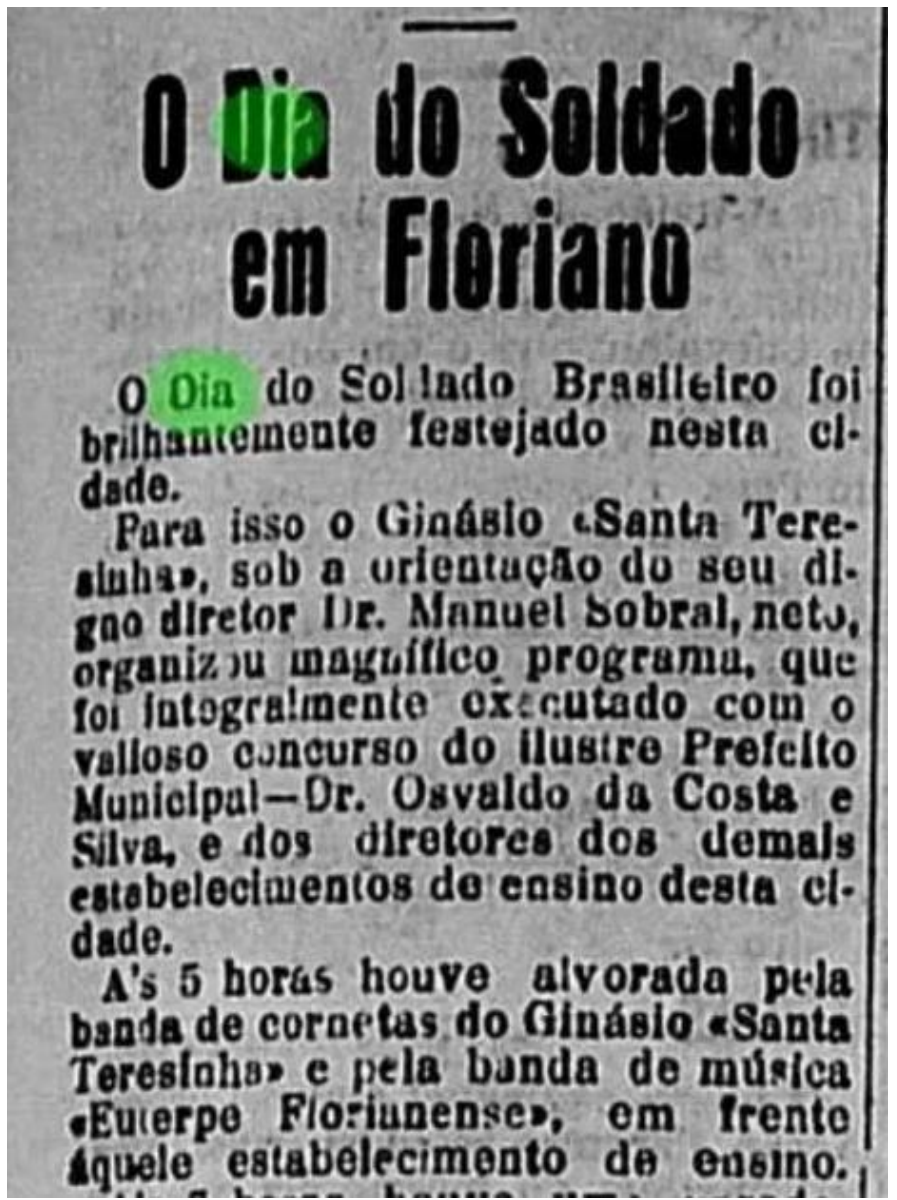

Fonte: O dia... (1943, p. 3).

O Ginásio Santa Teresinha, que tinha a banda Euterpe Florianense, foi criado em 1934 pela emérita professora Iracema Abreu, mais conhecida como dona Morena, com a denominação de Jardim da Infância Santa Teresinha. Em 1938, o então promotor Manoel Sobral Neto - educador de gerações - comprou o citado instituto e, nos anos 1940, criou, então, com o nome de Ginásio Santa Teresinha, o curso ginasial de Floriano (MELO, 2011). Como se pode ver na imagem a seguir, a escola ia às ruas em comemorações, festividades escolares e cívicas acompanhada ao som de sua banda. 
Música e banda: tessitura da inserção social no Piauí (1905-1948)

Figura 5 - Desfile do Ginásio Santa Teresinha

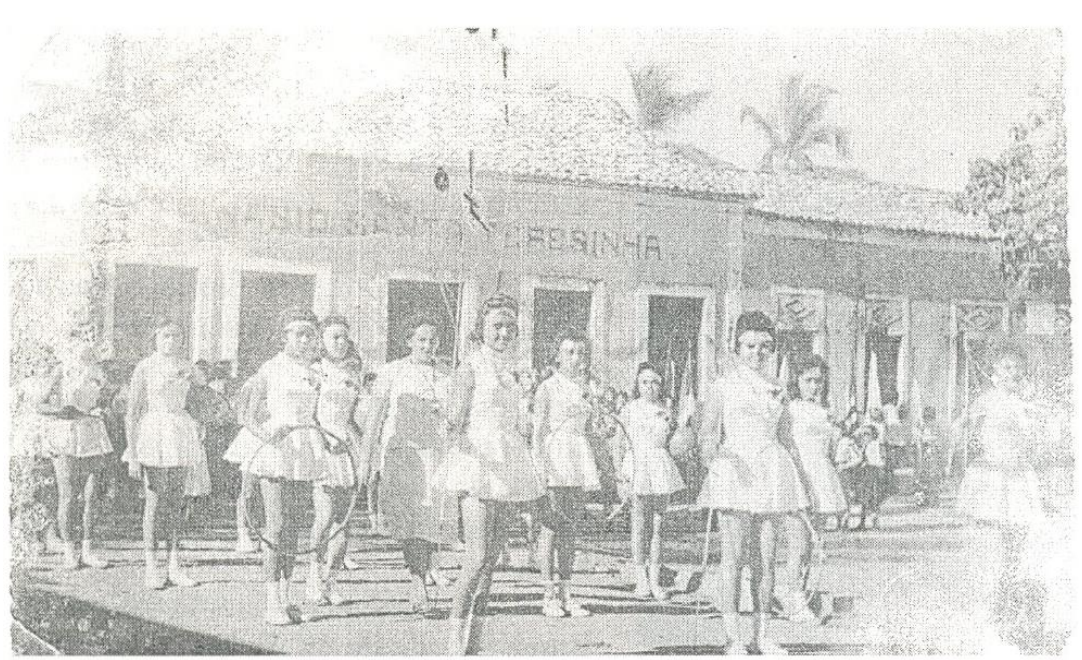

Fonte: Melo (2011, p. 1).

Outro espaço educativo que dispunha de banda de música era o Seminário da Parnaíba. Encarregado de formar os novos párocos, não ficava alheio aos eventos religiosos importantes na cidade. Essa afirmação sustenta-se com a criação de sua banda de música, que se apresentava, sobretudo, em festas religiosas, como a festa da igreja Nossa Senhora do Amparo, na cidade de Parnaíba, como podemos conferir na imagem a seguir:

Figura 6 - Nota sobre a banda de música do Seminário da Parnaíba

Rev. Caminhos da Educação: diálogos, culturas e diversidades, Teresina, v. 3, n. 1, p. 19-34, Jan./Abr. 2021 


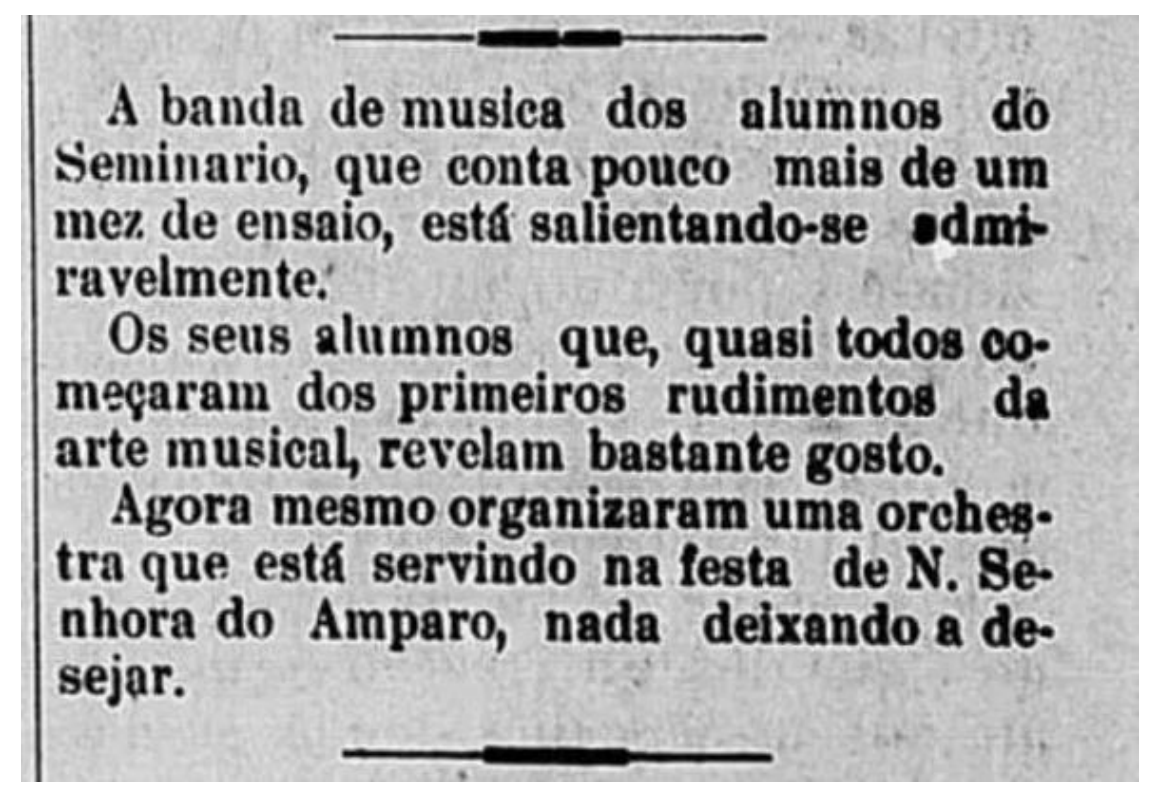

Fonte: União... (1907, p. 2).

É importante sublinhar que esse movimento de fazer musical não ocasionou a criação de escolas voltadas ao ensino de Música no estado do Piauí naquele momento, mesmo com a presença de várias bandas de música como essas. Todavia, seus integrantes, posteriormente, criaram a principal escola de música da cidade. Para Filho (2009, p. 116), as bandas de música eram instituições “[...] ao mesmo tempo singela e complexa, campo propício para o aprendizado das técnicas instrumentais e para a formação de um campo de trabalho específico para o músico instrumentista" (FILHO, 2009, p. 116).

No Piaú, entretanto, o ensino de Música desenvolvido dentro das bandas é
bastante limitado nesse sentido, proporcionando um aprendizado essencialmente
voltado para a aquisição da habilidade técnica junto ao instrumento escolhido e à
aquisição de repertório adequado às necessidades da banda. Todas essas
deficiências têm inviabilizado a utilização do ensino musical proporcionado pelas
bandas de música como ferramenta de musicalização dentro do currículo, de
maneira que, nas poucas escolas onde existem, as bandas são sempre uma
atividade extra-curricular (FILHO, 2009, p. 125).

Ou seja, essas bandas agiam de forma mais prática e improvisada, não necessariamente com um ensino institucional. Apenas em 1981, com a criação da Escola de Música de Teresina, surge a primeira instituição do gênero no Piauí. A partir de 2016, passa a ser chamada de Escola Estadual de Música Possidônio Queiroz. Para Silva (2020), é possível interpretar a instituição como uma das principais iniciativas do estado do Piauí no que se refere ao ensino de música. Sua criação e consolidação deu-se em virtude de parcerias institucionais estabelecidas pelos educadores musicais com o governo do Estado vigente à época, envolvendo sujeitos que atuaram diretamente na Escola no período.

Rev. Caminhos da Educação: diálogos, culturas e diversidades, Teresina, v. 3, n. 1, p. 19-34, Jan./Abr. 2021 
Música e banda: tessitura da inserção social no Piauí (1905-1948)

Percebe-se que as bandas de música estiveram nos mais diversos espaços de sociabilidade do Piauí, seja em encontros políticos, inaugurações da municipalidade, sociedades artísticas, mecânicas e liberais, clubes sociais, festas cívicas e religiosas e instituições educativas. Isso nos faz inferir que a música, materializada através de bandas, esteve fortemente presente no Piauí.

\section{Considerações finais}

Por tudo isso, entendemos que a música é um dos mais importantes veículos de transmissão do conhecimento e elemento facilitador do contato com bens culturais. Essa assertiva põe em evidência a mediação: a música por si só é um grande propiciador, pois ela ensina e é, em si, mediadora.

No Piauí do século XX, entre os anos de 1905 e 1948, foi possível perceber que o fenômeno histórico e educativo da música foi associado (de forma mediadora) ao "civilizarse”. Estava no seio da sociedade piauiense. Um desses eixos de transmissão eram as bandas, que estavam inseridas nos variados espaços de sociabilidade. Foi constatado, nos jornais correlacionados com a bibliografia selecionada, que as bandas de música estavam presentes em encontros políticos, inaugurações da municipalidade, sociedades artísticas, mecânicas e liberais, clubes sociais, festas cívicas e religiosas e instituições educativas. Trata-se de fios e rastros que tecem a situação das bandas de música no Piauí.

\section{Referências}

AZEVEDO, Breno Fabrício Terra; BASTOS, Helvia Pereira Pinto. Mineração de dados textuais educacionais: experiências e perspectivas para a análise de postagens em fóruns de discussão. In: PEIXOTO, Gilmara Teixeira Barcelos et al. (orgs.). Tecnologias digitais na educação: pesquisas e práticas pedagógicas. Campos dos Goytacazes: Essentia, 2015. p. $18-40$.

BARBOSA, Rui. Reforma do ensino primário e várias instituições complementares da instrução pública (1883). Rio de Janeiro: Ministério da Educação e Saúde, 1947. 
BURKE, Peter. A Revolução Francesa da Historiografia: a Escola dos Annales 19291989. São Paulo: Editora Universidade Estadual Paulista, 1991.

CAUSA gosto entreter os visitantes. Diario do Piauy, Teresina, ano 2, n. 58, p. 3, 14 abr. 1912.

CERTEAU, Michel de. A invenção do cotidiano. Rio de Janeiro: Vozes, 1994.

CASPARD, Pierre; CASPARD, Penélope. Imprensa pedagógica e formação contínua de professores primários (1815-1939). In: CATANI, Denice; BASTOS, Maria Helena Camara (orgs.). Educação em Revista: a imprensa periódica e a história da educação. São Paulo: Escrituras, 1997. p. 33-46.

DE AMARANTE. [Sem título]. Diario do Piauy, ano 1, n. 145, Teresina, 20 set. 1911.

ELIAS, Norbert. O processo civilizador: formação do estado e civilização. Rio de Janeiro: Jorge Zahar Ed., 1993.

ESTATUTOS do "Artistico Foot-Ball Club". O Artista, Teresina, ano 1, n. 1, p. 3, 22 set. 1918.

FILHO, João Valter Ferreira. História e memória da educação musical no Piauí: das primeiras iniciativas à universidade. 2009. Dissertação (Mestrado em Educação) Programa de Pós-Graduação em Educação, Universidade Federal do Piaú, Teresina, 2009.

INAUGURAÇÃO de usina. O Monitor, Teresina, ano 4, n. 114, 1 jan. 1909.

JAZZ-BAND de Campo-Maior. Gazeta, Teresina, ano 23, n. 1439, p. 4, 17 nov. 1943.

JORNAL NORTISTA. [Sem título]. Nortista, Parnahíba, ano 1, n. 47, 23 nov. 1901. MELO, Janclerques Marinho de. Retratos. In: MELO, Janclerques Marinho de. Portal de Floriano. [S. l.], 28 abr. 2011. Disponível em: http://portaldefloriano.blogspot.com/2009/04/retratos_28.html. Acesso em: 10 ago. 2020.

MELO, Pedro Thiago Costa. Talvez, uma percepção diferente de D. Júlia da obra O Manicaca: "sou dona do meu chibiu!". In: MELO, Pedro Thiago Costa. causosEcousas. Teresina, 26 jan. 2019. Disponível em: http://cousass.blogspot.com/2019/01/talvez-umapercepcao-diferente-de-d.html. Acesso em: 23 jul. 2020.

MINAYO, Maria Cecília de Souza. O conceito de representações sociais dentro da sociologia clássica. In: GUARESCHI, Pedrinho; JOVCHELOVITCH, Sandra (orgs.). Textos em representações sociais. 4. ed. Petrópolis: Vozes, 2000. p. 34-113.

MONTI, Ednardo Monteiro Gonzaga. Polifonias políticas, pedagógicas e identitárias: Villa-Lobos no Instituto de Educação do Rio de Janeiro na Era Vargas. Tese (Doutorado em Educação) - Programa de Pós-Graduação em Educação, Universidade do Estado do Rio de Janeiro, Rio de Janeiro, 2015. 
Música e banda: tessitura da inserção social no Piauí (1905-1948)

NÓVOA, Antônio. A imprensa de educação e ensino: repertório analítico (século XIXXX). Lisboa: Instituto de Inovação Educacional, 1993.

O DIA do soldado em Floriano. Gazeta, Teresina, ano 23, n. 1439, p. 3, 17 nov. 1943.

QUEIROZ, Teresinha de Jesus Mesquita de. A importância da borracha de maniçoba na economia do Piauí: 1900-1920. 2 ed. Teresina: FUNDAPI, 2006.

ROCHA SOUSA, Antonio Carlos. Banda de Música da Polícia Militar do Estado do Piauí: história, acervo e memória, de 1875 a 2013. Teresina: [s. n.], 2014.

SCHWARCZ, Lilia Moritz; STARLING, Heloisa Murgel. Brasil: uma biografia. São Paulo: Companhia das Letras, 2015.

SILVA, Juniel Pereira da. Casa de sons - Escola de Música de Teresina (1981 - 1991): sujeitos e práticas educativas entre salas e palcos. 2020. Dissertação (Mestrado em Educação) - Programa de Pós-Graduação em Educação, Universidade Federal do Piauí, Teresina, 2020.

SILVA, Laila Pedrosa da. "Somos parte integrante da nação": o Piauí nas exposições do início do século XX e os debates sobre modernização e integração da região. 2019.

Dissertação (Mestrado em História das Ciências e da Saúde) - Programa de Pós-Graduação em História das Ciências e da Saúde, Fundação Oswaldo Cruz, Rio de Janeiro 2019.

SILVA, Lélio Eduardo Alves da. Musicalização através da banda de música escolar: uma proposta de metodologia de ensaio fundamentada na análise do desenvolvimento musical dos seus integrantes e na observação da atuação dos "Mestres da banda". 2010. Tese (Doutorado em Música) - Programa de Pós-Graduação em Música, Universidade Federal do Estado do Rio de Janeiro, Rio de Janeiro, 2010.

UNIÃO. O Apostolo, Teresina, ano 1, n. 12, p. 3-4, 14 ago. 1907.

RECEBIDO: 01/02/2021

APROVADO:03/04/ 2021
RECEIVED: 01/02/2021

APPROVED: 03/04/ 2021
RECIBIDO: 01/02/ 2021

APROBADO: 03/04/ 201 